\title{
Students' attitudes to ethics in the medical school curriculu瞍
}

\author{
Earl E Shelp Department of Community Medicine
}

Michael L Russell Departments of Medicine, CommunityMedicine and Psychiatry and

Nellie P Grose Department of Family Medicine, Baylor College of Medicine, Houston, Texas, United States

\section{Authors' abstract}

A survey of 106 medical students assessing their interest in and attitudes to medical ethics in the curriculum is reported by the authors. Results indicate that 64 per cent of the students rated the importance of medical ethics to good medical care as high or critical and 66 per cent desired to learn more about the topic. However, in reports of patient encounters identifying ethical issues, less than six per cent of the students reported a frequency of more than one such patient encounter per week. The students also demonstrated a greater awareness of more obvious ethical issues than of more subtle, less publicised issues. When asked how medical ethics should be taught, the students clearly affirmed a desire for an integrated exposure to the subject throughout the medical curriculum. Possible implications of these findings for medical education are discussed.

Ever increasing efforts to teach medical ethics have been reported in the literature. These reports can be classified generally as surveys, descriptions, and evaluations. Robert Veatch and associates have reported survey data of medical ethics education in American medical schools (I)-(3). Other reports have described institutional programmes or specific courses in medical ethics in the United States, Great Britain, and Europe indicating their objectives, justification, content, structure, and faculty (2), (4), (5)-(II). Finally, efforts to evaluate postgraduate and continuing education in medical ethics have appeared (IO), (12). However, apart from a report by Levine, Scott, and Curran (10) there does not appear to be any published research which has measured the interests and attitudes of medical students towards the study of medical ethics.

The present study attempted to examine student attitudes to the teaching of medical ethics in the undergraduate medical curriculum. A questionnaire was designed to aid in the development of a curriculum in medical ethics responsive to perceived needs at Baylor College of Medicine. Answers were sought to six basic questions. How important and desirable is ethics to the curriculum? Are there identifiable characteristics to account for student interest in ethics? How aware of medical ethical issues are medical students, and how able are they to identify them? Is there a correlation between expressed interest in ethics and participation ôn established educational opportunities in ethics?

\section{Method}

Baylor College of Medicine has a threeundergraduate programme with an optional foupth year with enrolment per year of 168 students. During the study period, I-2I June 1979, there were 224 basic science, 275 clinical, and 549 graduating students. Fifty students were randomly selected from each level. Each student was mailed a questionnaire soliciting information on age, ethnicity, marital status, family and educational background, attendance at medical ethics courses and lectures at Baylor College of Medicine, interest in additional courses, awareness of ethical issues, and opinions on the importance of medical ethics in the curriculum. Follow-up to non-respondents inclueded mailing a second questionnaire ten days after ohe initial mailing, and a phone call twenty days lateri

\section{SAMPLE CHARACTERISTICS}

The response rate was 76 per cent ( 38 of 50 ) for beth the basic science and clinical levels, and 60 per cent (30 of 50) for the graduating students, giving a mean response rate of 70 per cent. The respondents 77 per cent males, 23 per cent females, which fras representative of the student population, and included blacks -2 per cent, Spanish surnames 4 per cent, Caucasian - 91 per cent, and others -4 要er cent. The Caucasians were slightly over-represenfed in the sample. The marital status of the sample was as follows: married - 3I per cent, never marrie 68 per cent, divorced - I per cent. For the total sample, the percentage of students who enrolletin elective ethics courses at Baylor College of Mediaine were: no courses -62 per cent, I course - 15 iger cent, 2 courses - 17 per cent, 3 courses -6 per ce्ght. In addition, 24 per cent of the students reported attending a lecture on medical ethics in the inge months prior to the study. When asked how of they read about medical ethics, 13 per cent reporfed 'never', 4 per cent reported 'only when faced withan issue', 72 per cent reported 'infrequently', and $\mathrm{I} I$ p్er cent reported 'regularly'.

\section{Results}

ANALYSIS OF STUDENT ATTITUDES

The students were asked to rate the importance of medical ethics to good medical care on a 5 paint 
Likert-type scale (ie, no, low, moderate, high, and critical importance). For the total sample, the mean of the students' ratings was $3.77, \mathrm{sd}=0.87$ ( $4=$ high importance), with 64.I per cent rating the importance of medical ethics as 'high' or 'critical' and 3I.I per cent as 'moderate'. No significant differences were observed among the ratings by the three student levels. Additional analyses indicated that no significant differences in the ratings were associated with the following student characteristics:

a) presence of physician or social scientist in the student's family,

b) previous educational courses in ethics, theology, philosophy, or social sciences, and

c) previous enrolment in a medical ethics course at Baylor College of Medicine. However, of those students who had a prior educational history in theology and who had taken a medical ethics course at Baylor College of Medicine $(n=I I)$, only 36.4 per cent rated medical ethics of 'high' or 'critical', and 54.5 per cent of 'moderate', importance to good medical care.

The students indicated the frequency of their involvement in medical cases which raised ethical questions over the past six months (see Table I). Whereas about 40 per cent of the clinical students and rather more of the graduating students reported medical cases involving ethical issues one or more times per week, not surprisingly very few of the basic science students reported this frequency. The analysis compared these data with expected frequencies of encounters with medical cases involving ethical issues. A significantly greater percentage of basic science students reported 'never encountering' these cases, a significantly greater percentage of clinical students reported encountering these cases on a 'once per month' basis, and a significantly greater percentage of clinical and graduating students reported encountering these cases on a

Table I Reported frequency of involvement in the past six months in medical cases which raised ethical issues

\begin{tabular}{|c|c|c|c|c|c|c|c|c|}
\hline \multirow[b]{2}{*}{ Frequency } & \multicolumn{2}{|c|}{$\begin{array}{c}\text { Basic } \\
\text { Science }\end{array}$} & \multicolumn{2}{|c|}{ Clinic } & \multicolumn{3}{|c|}{ Graduating } & \multirow{2}{*}{ Total } \\
\hline & $N$ & $\%$ & $N$ & $\%$ & $N$ & $\%$ & $N$ & \\
\hline \multirow{6}{*}{$\begin{array}{l}\text { I per month } \\
\text { I per week } \\
\text { I per day } \\
\text { More than } \\
\text { I per day }\end{array}$} & 29 & $76.3^{A}$ & 6 & 15.8 & 5 & 16.7 & 40 & 37.7 \\
\hline & 8 & 2I.I & 17 & $44.7^{\circ}$ & II & 36.7 & 36 & 34.0 \\
\hline & I & 2.6 & 12 & $31.6^{\circ}$ & II & $36.7^{d}$ & 24 & 22.6 \\
\hline & 0 & $\circ$ & $\mathbf{I}$ & 2.6 & 2 & 6.7 & 3 & 2.8 \\
\hline & 0 & 0 & 2 & 5.3 & I & $3 \cdot 3$ & 3 & 2.8 \\
\hline & 38 & & $\overline{38}$ & & 30 & & 106 & \\
\hline
\end{tabular}

$=\mathrm{p}<0.01, \chi^{2}=58.8, \mathrm{df}=8$

$\mathrm{b}=\mathrm{p}<0.01, \chi^{2}=22.4, \mathrm{df}=8$

$c=p<0.05, \chi^{2}=16.7, \mathrm{df}=8$

${ }^{d}=\mathrm{p}<0.05, \chi^{2}=17.8, \mathrm{df}=8$ 'once per week' basis. These data presumably simply reflect the less frequent patient contact of the basic science students as compared with the clinical or graduating students.

Students who identified ethical issues (66 of 106-62 per cent) were asked to describe one case. Seventy-six case descriptions were reported (see Table II). An examination of the cases described by the students indicated a clear concern by the students for the more dramatic cases in which ethical issues were raised, and much less discussion of cases which were not life threatening but involved more subtle ethical issues.

\section{MRDICAL ETHICS IN THE CURRICULUM}

The students were asked whether they had a general interest in learning more about medical ethics. While as a group, the students' response was clearly affirmative (yes $=66$ per cent), the percentage of students varied across the student levels (see Table III).

Table II Ethical issues in patient care encountered by 66 students over the past six months

\begin{tabular}{lcc}
\hline & \multicolumn{2}{c}{ Approximate } \\
Ethical issues & Frequency & Percentage \\
\hline Care of terminal patient & 34 & 45 \\
Patient or family management & I I & I4 \\
Truth telling & Io & I3 \\
Consent for standard treatment & 5 & 7 \\
Determination of death & 4 & 5 \\
Proxy consents for children & & \\
$\quad$ and incompetents & 3 & 4 \\
Resource allocations & 2 & 3 \\
Access to health care & I & I \\
Confidentiality & I & I \\
Care of chronically ill & I & I \\
Patient abuse & I & I \\
Abortion & I & I \\
Artificial insemination & I & I \\
Sterilisation & I & I \\
\hline
\end{tabular}

Table III Number of students by level who reported a general interest in learning more about medical ethics

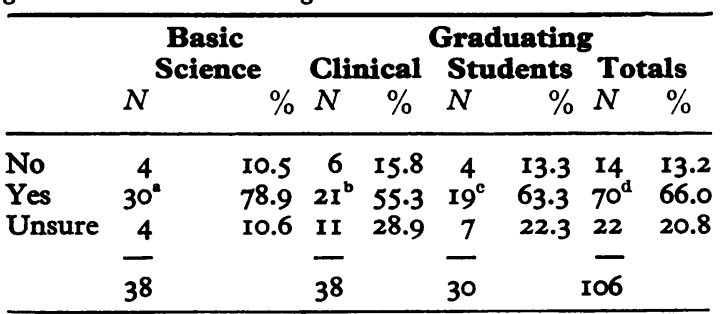

$=\mathrm{p}<0.0 \mathrm{r}, \chi^{2}=\mathrm{I7.79}, \mathrm{df}=2$

b $=$ N.S.

o $=\mathrm{p}<0.05, \chi^{2}=7.50, \mathrm{df}=2$

$\mathrm{d}=\mathrm{p}<0.01, \chi^{2}=29.58, \mathrm{df}=2$

Analysis note: The $\chi^{2}$ calculations compared the observed frequencies of 'yes' vs. 'no' responses after the number of 'unsure' responses had been equally assigned to each category. The expected frequencies were then assumed to be so per cent for each category. 
While two thirds of all students reported a desire to learn more about the topic, they were divided as to whether the topic should be part of a required course (yes $=29$ per cent, no $=47$ per cent, unsure $=24$ per cent). However, the students clearly supported medical ethics as an elective course (yes $=82$ per cent, no $=$ ro per cent, unsure $=7$ per cent), as a lecture at Grand Rounds (yes $=55$ per cent, no $=28$ per cent, unsure $=17$ per cent), and as a part of a discussion at rounds (yes $=83$ per cent, no $=$ ro per cent, unsure $=7$ per cent). Further, 59 per cent of the students supported the teaching of medical ethics at all levels of the curriculum while 13 per cent preferred to include it only at the basic science level, 22 per cent wanted it only at the clinical level and 4 per cent wished not to have it at all. No differences were observed by student level for these ratings.

\section{Discussion}

It was assumed that certain characteristics, such as familial or educational background, would account for an expressed interest in, and perceived importance of, medical ethics. These assumptions proved false. Exceptions were the students with religious studies in their educational history, who as a group rated the study of ethics to be less important to good medical care than did their peers. This lower rating appears to contradict a presumption that religiously oriented individuals would favour more highly the study of ethics. One could speculate that these students thought that moral individuals (as indicated by an interest in religion) do not require study in ethics focused on a specific area of human activity. They may have thought that a person's religious moral principles are universally applicable and provide a sufficient guide for conduct in the medical context. On the other hand, some traditions within Protestantism (eg, some interpretations of Luther's doctrine of two kingdoms or Calvin's understanding of calling and vocation) allow for a separation of one's religious commitments from one's vocational activity.

The origin of the rather broad and substantial approval of ethics teaching is uncertain. One hypothesis is that the general interest may be due to political and medico-legal discussions in the media and within professional groups. This explanation gains credibility when the students' descriptions of cases involving ethical questions are examined. The preoccupation with 'death and dying' may reflect the visibility of these concerns as well as uncertainties in the minds of the respondents. The infrequent mention of cases involving human sexuality may reflect a limited exposure to certain procedures, the more private nature of the interventions, or a more settled opinion on the part of the respondents even though these topics also are highly publicised.

The concern for truth-telling and patient man- agement may stem from more pragmatic interests than moral reflection. The intersection of moral d practical significance at this point may or may account for the heightened awareness of these matters when compared to other less sensational issues. Implicit in many of the case reports is interest in learning how to do something rather then any consideration of the moral question 'should it done at all ?'

The desire to learn more about medical ethics fluctuated across the three levels (see Table III). The pattern may reflect a change in the students' attitudes as they progressed through medical schogl. If so, the initial drop in interest during the clinieal rotation may be attributable to its non-reflect产, task-oriented, and skill-mastering emphasis. This emphasis is in contrast with the basic science programme where large amounts of data dy processed apart from interactions with patiergs. Thinking about and discussing moral questions may offer a welcomed change of pace and provide a mesps for students to relate their developing knowledge्্]to patients even if only through case presentations_or issue discussions. The increased interest of grasating students may reflect a concern to integrate their educational experiences into their ofn philosophy of medicine. These students nom recognise, in a manner never before realised, the responsibility they carry as physicians. While these speculations are suggested by the present datag a longitudinal study would be necessary to assess their validity.

The students' preference for integrating ethics throughout their medical education is particulafly interesting. A diverse and continuing exposure 70 the moral dimensions of medical care seems to ofter several benefits. First, it would perpetuate फुe humanitarian tradition within medicine. Secoud, faculty could role model, especially at rounds, the importance of moral practice to good medical care. Without this emphasis, the relevance and importance of medical ethics is condemned $7 y$ omission. Third, courses and rounds toget provide an opportunity for students to bridge ethigal theory and moral decision-making in medical practice. Fourth, it could assist students in defin their professional role, authority, responsibility, arpd identity.

The findings of this survey indicate that medieal students are not totally satisfied with a purgy technical-scientific medical education. A greater emphasis on the art of medicine, which would include clinical judgment, practical wisdom, ard moral sensitivity, might serve to promote the abigity of practitioners better to serve their patients amd contribute to the integrity of the profession कas servants of weakened humanity. The willingnessnof students to become familiar with this aspect of medical practice was demonstrated by this study

The present survey indicated a need to equp 
students to recognise and define the more subtle ethical issues in medicine as well as a need to enhance their understanding of the more obvious issues. An increased knowledge of the role of values and ethics in medical practice could have profound implications for modern health care. Instruction in these areas might contribute to the liberation of the profession from the misperceptions and unreasonable expectations of a demanding public. As a result, the public might be moved toward a lesser dependency on medicine as the solution to all problems and a greater acceptance of responsibility for their own health and well-being.

A neglect of ethics in medical education would appear non-responsive to expressed desires. A positive response would appear to require little additional institutional financial commitment. Additional faculty with advanced training in medical ethics and medical humanities may be necessary. But, more important to a positive institutional response would be a willingness on the part of the medical faculty to become informed about these matters and to include discussions of them in the routine course of instruction. It would appear that more is to be gained than lost from a medical curriculum that includes medical ethics.

\section{References}

(I) Veatch R M, Fenner D. The teaching of medical ethics in the United States of America. Fournal of medical education 1975; I: 99-103.
(2) Veatch $\mathbf{R} \mathbf{M}$, Faylin W, Morgan C. eds. The teaching of medical ethics. Hastings-on-Hudson, N. Y., Hastings Center, 1973: 97-102.

(3) Veatch R M, Sollitto S. Medical ethics teaching: Report of the National Medical School Survey. fournal of American medical association 1976; 235: 1030-1033.

(4) Blomquist C. The teaching of medical ethics in Sweden. Fournal of medical ethics 1975; I: 96-98.

(5) Dennis K J, Hall M R P. The teaching of medical ethics at Southampton University Medical School. fournal of medical ethics 1977; 3: 183-185.

(6) DeWachter M A M. Teaching medical ethics: University of Nijmegen, the Netherlands. fournal of medical ethics $1978 ; 4: 84-88$.

(7) Boyd K, Currie C, Thompson I E, Tierney A. Teaching medical ethics: University of Edinburgh. fournal of medical ethics 1978; 4: 14I-145.

(8) Jones J S P, Metcalfe D H H. The teaching of medical ethics in Nottingham Medical School. fournal of medical ethics 1976; 2 : 83-86.

(9) Sporken P. The teaching of medical ethics in Maastricht, The Netherlands. Fournal of medical ethics 1975; I: 18I-183.

(Io) Levine M D, Scott L, Curran W J. Ethics rounds in a Children's Medical Center: Evaluation of a hospital-based program for continuing education in medical ethics. Pediatrics 1977; 60: 202-208.

(II) Keller Jr A H. Ethics/human values education in the Family Practice Residency. Fournal of medical ethics 1977; 52: 107-116.

(I2) Jellinek $M$, Parmelee $D$. Is there a role for medical ethics in postgraduate psychiatry courses? American journal of psychiatry 1977; 134: 1438-1439. 